\title{
Cytotoxicity of Frutalin on Distinct Cancer Cells Is Independent of Its Glycosylation
}

\author{
Carla Oliveira $^{1}$, Ana Isabel Freitas ${ }^{2}\left(\mathbb{D}\right.$, Nair Campos $^{3}$, Lucília Saraiva $^{3}\left(\mathbb{D}\right.$ and Lucília Domingues ${ }^{2, *(D)}$ \\ 1 CBQF-Centro de Biotecnologia e Química Fina-Laboratório Associado, Universidade Católica Portuguesa, \\ Escola Superior de Biotecnologia, Rua Diogo Botelho 1327, 4169-005 Porto, Portugal; cmoliveira@porto.ucp.pt \\ 2 CEB-Centre of Biological Engineering, University of Minho, 4710-057 Braga, Portugal; \\ ana.isabel.freitas@ceb.uminho.pt \\ 3 LAQV/REQUIMTE, Laboratório de Microbiologia, Departamento de Ciências Biológicas, Faculdade de \\ Farmácia, Universidade do Porto, 4050-313 Porto, Portugal; naircampos@gmail.com (N.C.); \\ lucilia.saraiva@ff.up.pt (L.S.) \\ * Correspondence: luciliad@deb.uminho.pt; Tel.: +351-253-604-405
}

Citation: Oliveira, C.; Freitas, A.I.; Campos, N.; Saraiva, L.; Domingues, L. Cytotoxicity of Frutalin on Distinct Cancer Cells Is Independent of Its Glycosylation. Molecules 2021, 26, 4712. https://doi.org/10.3390/ molecules26164712

Academic Editors: Claudio Tabolacci and Ravirajsinh N. Jadeja

Received: 6 July 2021

Accepted: 31 July 2021

Published: 4 August 2021

Publisher's Note: MDPI stays neutral with regard to jurisdictional claims in published maps and institutional affiliations.

Copyright: (c) 2021 by the authors. Licensee MDPI, Basel, Switzerland. This article is an open access article distributed under the terms and conditions of the Creative Commons Attribution (CC BY) license (https:// creativecommons.org/licenses/by/ $4.0 /)$.

\begin{abstract}
Frutalin is a plant lectin with beneficial immunobiological action, although the access to its active form is still restricted. Moreover, there is a knowledge gap on isoform activity and glycosylation impact on its bioactivity, and recombinant production protocols were seen as ineffective. Here, a simpler and faster production and purification protocol was developed, attaining a yield of purified frutalin 3.3-fold higher than that obtained previously. Hemagglutination assays confirmed that this frutalin isoform could not agglutinate rabbit erythrocytes, while maintaining the native tetrameric structure, as indicated by DLS analysis, and strong interaction with methyl-alpha-galactose, in fluorescence spectroscopy studies. The cytotoxicity of the recombinant frutalin isoform was shown in a broad panel of human cancer cells: colon (HCT116), melanoma (A375), triple-negative breast cancer (MDA-MB-231), and ovarian (IGROV-1). Treatment with 8.5-11.8 $\mu \mathrm{M}$ TrxFTL reduced proliferation of all cancer cells to half in $48 \mathrm{~h}$. This anti-proliferative effect encompasses the p53 pathway since it was significantly reduced in p53-null colon cancer cells (HCT116 p53-/-; $\mathrm{GI}_{50}$ of $25.0 \pm 3.0 \mu \mathrm{M}$ ),

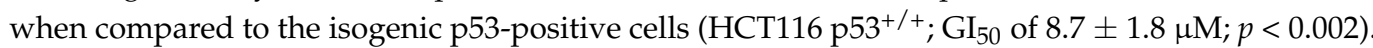
This recombinantly produced frutalin isoform has relevant cytotoxic effect and its biological activity is not dependent on glycosylation. The developed E. coli production and purification protocol generates high yield of non-glycosylated frutalin isoform with potent cytotoxic activity, enabling the development of novel anticancer p53-targeting therapies.
\end{abstract}

Keywords: recombinant frutalin; isoforms; Escherichia coli; targeted anticancer therapy; p53

\section{Introduction}

Frutalin lectin has been extensively studied in recent years, mainly in immunobiological research, due to its outstanding biological properties. These include, for example, gastroprotection [1], tissue repair, regeneration and chronic wound healing [2], antidepressant-like effect [3], and antitumor activity, resulting from the recognition of cancer-associated oligosaccharides [4]. As other lectins, frutalin isolated from its natural source (breadfruit seeds) is a mixture of isoforms [5]. Slight (but important) differences in amino acids sequences (from 3 to $7 \%$ ) were identified in frutalin isoforms [6]. Such differences also account for a partial glycosylation in final samples. It is well-known that each lectin isoform can interact differently with cells, leading to distinct cytoagglutinatination and cytotoxic activities [5]. It is still unclear the role of glycosylation on such biological diversity, while it seems a critical factor on lectins stability [7]. Sample heterogeneity, together with geographical and seasonal source-dependence, and low purification yield, restricts further exploitation of the biomedical properties of frutalin. The bacteria Escherichia coli was tested as recombinant host by employing direct cDNA cloning and no 
fusion partners, but the production yield of soluble frutalin was low [6]. Still, recombinant frutalin revealed agglutination properties and carbohydrate-binding specificity similar to the native lectin [6]. On the other hand, the yeast Pichia pastoris has proven to be an effective alternative to obtain soluble, stable, and functional frutalin samples [8]. Interestingly, while native frutalin demonstrated a strong hemagglutinating activity, the recombinant frutalin did not present such capacity, which could either be due to hampering effects of yeast glycosylation or to an intrinsic characteristic of the cloned isoform [8]. Still, recombinant frutalin showed irreversible antiproliferative effect on HeLa cervical cancer cells, as native frutalin, and higher specificity as a biomarker of human prostate cancer $[4,9]$. Nonetheless, the production and purification process of frutalin in yeast was relatively slow, laborious, and resulted in modest yields [8].

With the great advances in fusion tag technology, for enhancing protein productivity and solubility, mainly in E. coli, several difficult-to-express proteins can now be produced in this host at reasonable yields [10-13]. As such, the aim of this study was to develop a novel strategy to produce and purify higher amounts of biologically active frutalin in E. coli, based on previously reported guidelines [11-14], and to study its antitumor activity. The molecular cloning approach employed in this work consisted in codon bias optimization, fusion with a solubility enhancer (TrxA) and a purification tag (6xHistag), followed by optimization of the culture conditions, and partners' cleavage. The target frutalin isoform was the one previously produced in P. pastoris [8]. Biological activity of the non-glycosylated frutalin obtained in E. coli was studied in vitro with rabbit erythrocytes and human cancer cells to ascertain its functionality and elucidate glycosylation importance on cells recognition. In addition, taking advantage of the improved production and purification of this recombinant frutalin isoform, its effect on different human cancer cell lines was for the first time evaluated.

\section{Results}

\subsection{Expression and Purification of Recombinant Frutalin}

Previously, the frutalin isoform of this work was successfully produced in P. pastoris by a 5-days induction process and purified by size exclusion chromatography (SEC) [8]. However, SEC led to a large dilution of recombinant frutalin during separation, while a concentration step was required for downstream applications. Hence, production of frutalin in yeast was found to be a time-consuming process of moderate yield (up to 20 milligrams per liter of culture), whilst the pure product consisted in a mixture of glycosylated and non-glycosylated forms [8]. Then, E. coli was employed as alternative host, but resulted in low soluble amounts of protein, despite optimization of codon usage and induction conditions (inducer concentration, temperature, and time of induction) (unpublished results). Furthermore, purification of soluble protein fraction by IMAC was very inefficient. Similar failure was found in the purification of frutalin produced in P. pastoris also by IMAC (unpublished results). The difficulty in purifying frutalin in these works using the small 6xHistag placed directly at its N-terminal or C-terminal, in bacteria and yeast, respectively, can be attributed to the location of these ends in the 3D frutalin structure, which according to the built model, are hidden (Figure 1). As it can be observed in the model, the C-terminal of $\alpha$ chains (silver) and the $\mathrm{N}$-terminal of $\beta$-chains (yellow) are placed inside the frutalin tetrameric structure (Figure 1), which presents the typical symmetric $\beta$-prism fold of jacalin-related lectins [15]. Importantly, in contrast to native frutalin, the first amino acid in $\alpha$ chain (Gly25) is not free in recombinant frutalin, but it is connected to $\beta$ chain by the linker TSSN (in red; Figure 1), being a key factor in the structural arrangement of the residues involved in the sugar-binding site of D-galactose (Gly25, Tyr146, Trp147, and Asp149) [15]. Not relevant for the model, but determinant for purification, the 6xHistag was placed at the $\mathrm{N}$-terminal of frutalin ( $\beta$ chain) via connection of 13 extra amino acids (which includes the TEV recognition site) (Table 1). These amino acids functioned as a spacing linker that improved the availability of 6xHistag to interact with the $\mathrm{Ni}^{2+}$ resin [11], thus enabling the efficiency of frutalin purification by IMAC. 


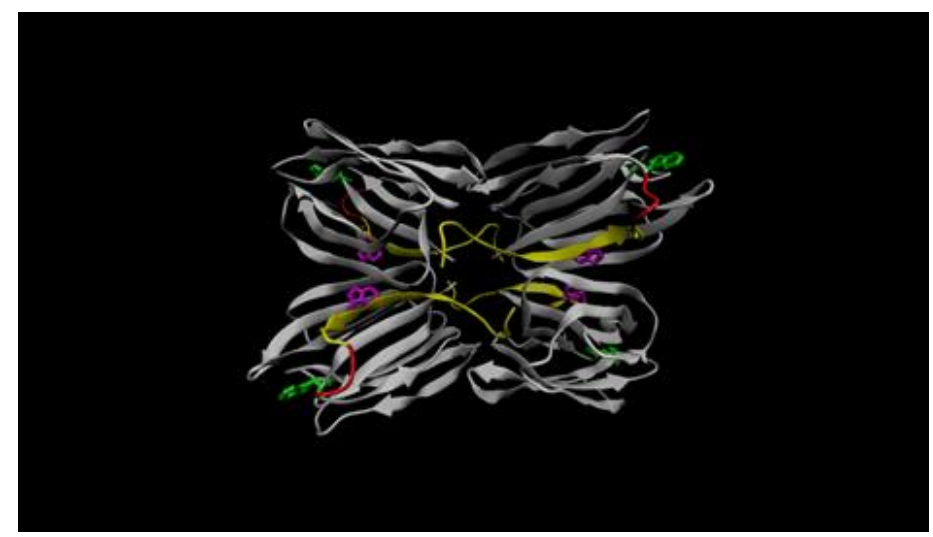

Figure 1. Putative molecular model of recombinant frutalin. The $\beta$ chains are colored in yellow and the $\alpha$ chains in silver in tetrameric structure. The four amino acid linker TSSN, which binds $\alpha$ and $\beta$ chains, is represented in red. The carbohydrate-binding site involves the N-terminus of the $\alpha$ chain and is formed by four key residues: Gly25, Tyr146, Trp147, and Asp149 [15]. Alterations in the spatial position of Trp residues upon frutalin binding to carbohydrates, principally in $\alpha$ chain, contribute to intrinsic fluorescence changes. The Trp residues are represented in green and magenta in $\alpha$ and $\beta$ chains, respectively.

Table 1. Amino acid sequences of frutalin produced in P. pastoris and E. coli, and calculated MW and pI.

\begin{tabular}{|c|c|c|c|}
\hline Frutalin Version & Amino Acid Sequence & Theoretical pI/Mw & Reference \\
\hline $\begin{array}{l}\text { Frutalin produced in } \\
\text { P. pastoris }\end{array}$ & $\begin{array}{c}\text { EFNQQSGKSQTVIVGPWGAKVSTSSNGKAFDDGAFTGIREIN } \\
\text { LSYNKETAIGDFQVVYDLNGSPYVGQNHKSFITGFTPVKISLD } \\
\text { FPSEYIMEVSGYTGNVSGYVVVRSLTFKTNKKTYGPYGVTSGT } \\
\text { PFNLPIENGLIVGFKGSIGYWLDYFSMYLSL * }\end{array}$ & $6.87 / 17381.52$ & [8] \\
\hline $\begin{array}{l}\text { Frutalin produced in E. coli in } \\
\text { fusion with TrxA (TrxFTL) }\end{array}$ & $\begin{array}{l}\text { MSDKIIHLTDDSFDTDVLKADGAILVDFWAEWCGPCKMIAP } \\
\text { ILDEIADEYQGKLTVAKLNIDQNPGTAPKYGIRGIPTLLLFKN } \\
\text { GEVAATKVGALSKGQLKEFLDANLAGSGSGHMHHHHHHS } \\
\text { SGENLYFQGAMGNQQSGKSQTVIVGPWGAKVSTSSNGKAF } \\
\text { DDGAFTGIREINLSYNKETAIGDFQVVYDLNGSPYVGNHKS } \\
\text { FITGFTPVKISLDFPSEYIMEVSGYTGNVSGYVVVRLTFKTNK } \\
\text { KTYGPYGVTSGTPFNLPIENGLIVGFKGSIGYWLDYFSMYLSL * }\end{array}$ & $5.97 / 31672.78$ & This work \\
\hline $\begin{array}{l}\text { Frutalin produced in E. coli } \\
\text { cleaved from TrxFTL (cFTL) }\end{array}$ & $\begin{array}{l}\text { GAMGNQQSGKSQTVIVGPWGAKVSTSSNGKAFDDGAFTGI } \\
\text { REINLSYNKETAIGDFQVVYDLNGSPYVGQNHKSFITGFTPV } \\
\text { KISLDFPSEYIMEVSGYTGNVSGYVVVRSLTFKTNKKTYGPYG } \\
\text { VTSGTPFNLPIENGLIVGFKGSIGYWLDYFSMYLSL * }\end{array}$ & $8.05 / 17421.61$ & This work \\
\hline
\end{tabular}

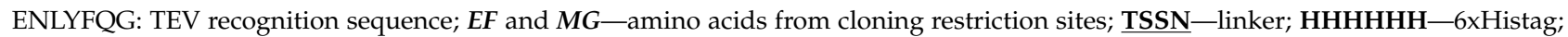
*-STOP codon.

Later, in a comparative tags study, the soluble production of another frutalin isoform was considerably improved by using different solubility enhancers, such as the TrxA, and the 6xHistag for purification by IMAC, being the protein soluble after partners' removal by TEV cleavage (Tobacco Etch Virus protease) [14]. Thus, a similar strategy was followed with the isoform selected for this work. Indeed, frutalin was produced in soluble form from $E$. coli BL21 in fusion with TrxA (TrxFTL) at high amounts. The fusion protein strategy boosted the availability of FTL by increasing its yield from few micrograms to dozens of milligrams per liter of E. coli culture, whilst simplifying the whole production and purification protocol. Roughly, $18 \mathrm{mg}$ of purified TrxFTL per gram of fresh biomass was obtained. IMAC revealed to be a simpler, easier, and quicker procedure than SEC for frutalin purification. Purified TrxFTL migrated in SDS-PAGE (Figure 2), as a homogeneous single band with a molecular weight close to its calculated molecular weight (MW) ( $32 \mathrm{kDa}$; Table 1). Purified cFTL could be observed in gel as a single band of $\sim 17 \mathrm{kDa}$ (Figure 2), which is also consistent with the predicted MW of the cloned frutalin sequence (Table 1). The same pattern in SDS-PAGE gel was also obtained by other frutalin isoform produced and purified in E. coli; however, at the $\mu \mathrm{g}$ per liter scale [6]. Thus, it can be concluded that fusion tag technology, 
together with optimization of codon usage and production and purification process, was essential for obtaining high pure yield of the difficult-to-express frutalin isoform.

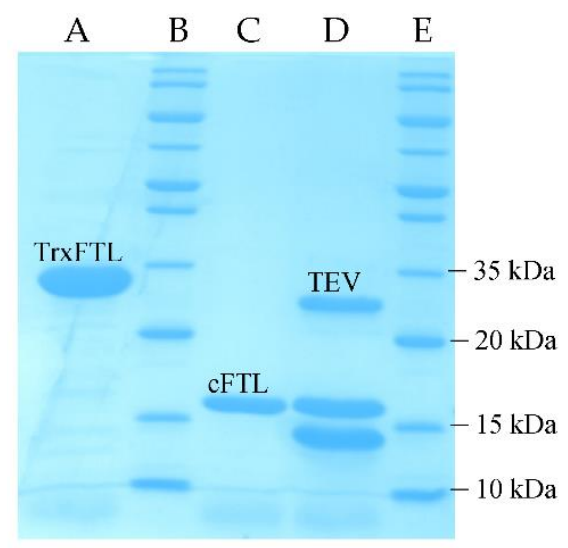

Figure 2. SDS-PAGE analysis of purification of TrxFTL and cFTL from E. coli. Lane A, FTL in fusion with TrxA (TrxFTL) purified by IMAC; Lanes B and E, molecular weight marker; Lane C, FTL cleaved and purified by reverse IMAC from TrxFTL; Lane D, products of digestion of TrxFTL with TEV protease (cFTL 17.4 kDa; TrxA 14.3 kDa).

\subsection{Protein Homogeneity Analysis by Dynamic Light Scattering (DLS)}

Protein homogeneity was studied by DLS using the intensity distribution method. In this method, high MW aggregates will disproportionately scatter more light in relation to smaller molecules, enabling detection even if present at a relatively low concentration [11]. Distribution is plotted against an apparent hydrodynamic radius, i.e., the radius of a hypothetical sphere that diffuses at the same rate as the particle under study, which is used to estimate the MW of the target molecule using the instrument software, and viceversa [11].

Frutalin is a tetrameric protein in nature $[8,16]$. If the recombinant frutalin obtained from E. coli acquires a tetrameric structure, the expected theoretical MW of TrxFTL would be $126 \mathrm{kDa}$ (monomer with $31.6 \mathrm{kDa}$; Table 1) and the theoretical MW of cleaved FTL from TrxFTL would be $70 \mathrm{kDa}$ (monomer with $17.4 \mathrm{kDa}$; Table 1). According to calculations of DLS software, apparent diameter of TrxFTL should be higher than that of cFTL, namely: $9.4 \mathrm{~nm}$ (4.7 nm of apparent radius) for TrxFTL and $7.3 \mathrm{~nm}$ (3.7 nm of apparent radius) for cFTL. These theoretical measurements are in complete agreement with what can be observed in Figure 3, where the population of TrxFTL and cFTL presents a diameter close to $7.5 \mathrm{~nm}$ and $9.5 \mathrm{~nm}$, respectively. Thus, DLS not only suggests tetrameric forms, for either TrxFTL or cFTL, but also that cFTL was perfectly cleaved form TrxFTL. Finally, TrxFTL appears to be highly homogenous, while cFTL seems to have some heterogeneity, due to the presence of high MW aggregates, as indicated by the presence of populations with high diameters (Figure 3A). The high homogeneity in TrxFTL samples enabled its purification without a SEC refining step. 
(A)

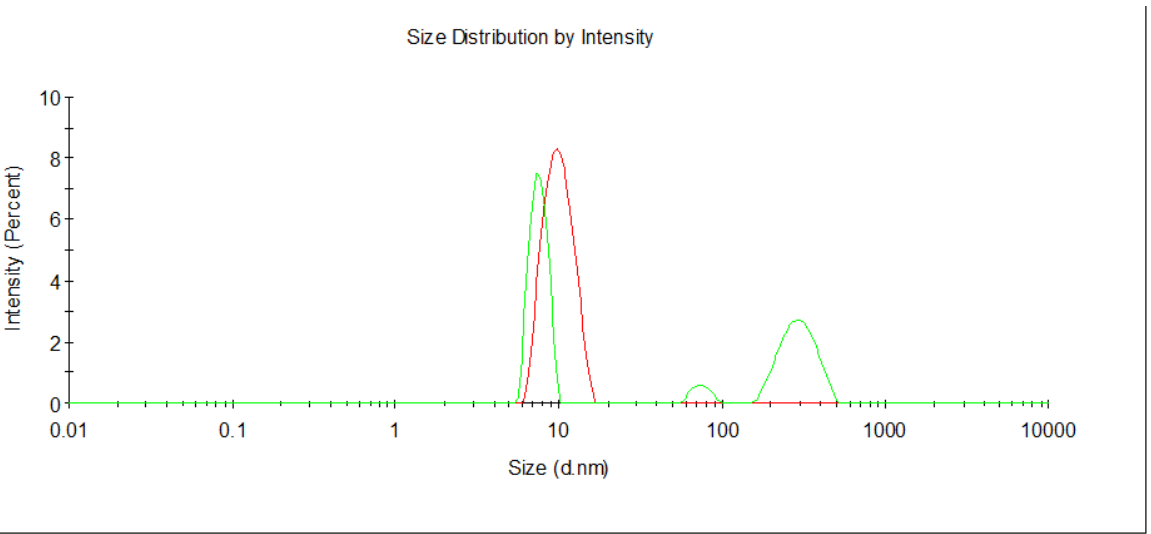

(B)

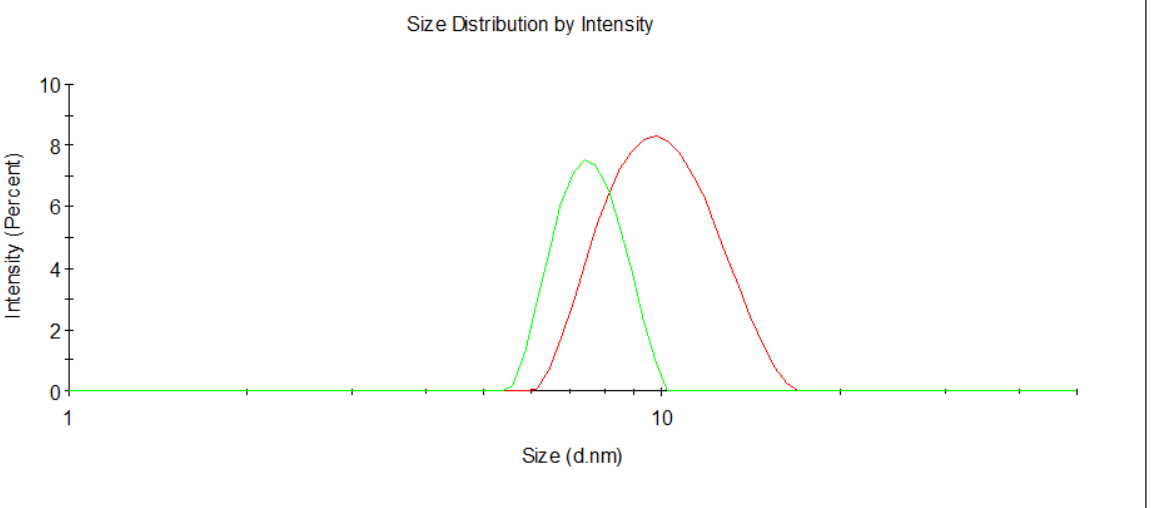

Figure 3. Size distribution by intensity for TrxFTL (red line) and FTL cleaved from TrxFTL (green line). (A) Size scale 0.01-10,000 nm diameter; (B) size scale 1-50 nm diameter. Estimated diameter for TrxFTL $(9.4 \mathrm{~nm})$ is higher than that estimated for cFTL $(7.3 \mathrm{~nm})$. Each curve represents the average of 10 independent measurements.

\subsection{Hemagglutinating Activity}

Native frutalin is known by its strong hemagglutinating activity towards rabbit erythrocytes [8]. Contrarily to native frutalin, no visible hemagglutinating activity was detected in these cells with purified TrxFTL or cFTL (Figure 4). A lectin obtained by recombinant means can lack hemagglutinating activity for basically three reasons: the lectin does not adopt the correct oligomeric conformation (hemagglutination activity presupposes at least two binding sites, e.g., by dimer formation); glycosylation, or other post-translational modification, in case of a lectin produced from a eukaryotic organism, exerts structural effects that can hamper this activity; and the cloned gene corresponds to a isoform that does not have this activity (many lectins are a mixture of isoforms with few amino acids differences, enough for giving them different biological activities). Previously, it was hypothesized that glycosylation might inhibit hemagglutinating activity of frutalin. However, the same frutalin version (same amino acids sequence) produced in a deglycosylated form in E. coli (this work) and in a partly-glycosylated form in P. pastoris (possibly, at Asn74) [8] did not present this activity, while another isoform with $92 \%$ of sequence identity obtained in E. coli was able to agglutinate rabbit erythrocytes [6]. Structural studies indicated tetrameric structure for all frutalin versions, including TrxFTL (this work). The isoform having agglutination capacity, while being non-glycosylated, differs in 12 amino acids in a total of 157 [6]. Thus, it can be assumed that the absence of hemagglutinating capacity in frutalin is dependent on the isoform (amino acid sequence), and not on the glycosylation. It is now clear that frutalin isoforms have different biological activities, regardless the presence or absence of glycosylation. Interestingly, the same conclusion 
about glycosylation was recently taken in the case of other lectins [7,17]. For example, the role of glycosylation of Curcuma longa rhizome lectin was studied by structural and activity assays conducted with wild-type lectin, deglycosylated form produced in E. coli, glycosylated form produced in P. pastoris, and glycosylated mutants N66Q and N110Q, also produced in P. pastoris. Circular dichroism, fluorescence spectroscopy, and hemagglutinating studies showed no differences in secondary or tertiary structures, or sugar binding properties, between native lectin and each recombinant lectin form under physiological $\mathrm{pH}$ [7]. Although glycosylation was found important to maintain correct lectin folding at acidic $\mathrm{pH}$ [7].

\section{(A)}

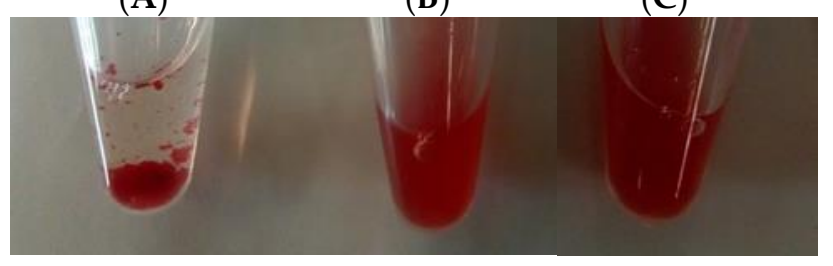

Figure 4. Photos of hemagglutinating assays carried out in $1.5 \mathrm{~mL}$ Eppendorfs with native frutalin (A), TrxFTL (B), and cFTL (C) for the higher concentration tested $(0.2 \mathrm{mg} / \mathrm{mL})$. A coagulum at the bottom of the Eppendorf is clearly visible in the presence of native frutalin (A), but not in the presence of TrxFTL (B) and cFTL (C).

\subsection{Interaction with Methyl- $\alpha$-Galactose}

The fluorescence emission spectrum of TrxFTL showed an emission maximum at $328 \mathrm{~nm}$. The same isoform produced in P. pastoris presented a fluorescence emission maximum at $333 \mathrm{~nm}$ [8]. Among many sugars studied, the recombinant frutalin produced in yeast demonstrated preference for methyl- $\alpha$-galactose, which led to high enhancements in frutalin fluorescence emission ( $35 \%$ ) [8]. Thus, the response of fluorescence emission of TrxFTL in presence of this sugar, at the same concentration $(100 \mathrm{mM})$, was analyzed. Similarly, a large increase $(\sim 46 \%)$ in the maximum fluorescence emission of TrxFTL was observed in the presence of methyl- $\alpha$-galactose (Figure 5). This result confirms that TrxFTL also binds to this sugar. No interaction with D-galactose was detected. Most probably, TrxFTL has identical sugar affinity to recombinant frutalin produced in yeast. According to previous studies, recombinant frutalin and jacalin produced in E. coli presented a 100-fold lower affinity for methyl- $\alpha$-galactose (association constants in the order of $10^{2} \mathrm{M}^{-1}$ ) than the corresponding native lectins (association constants in the order of $10^{4} \mathrm{M}^{-1}$ ). This is due to the absence of a proteolytic event in the recombinant host related to the cleavage of the four amino acid peptide "T-S-S-N", which connects the two polypeptides (alphaand beta-chain) that comprise the lectin $[8,18]$. Peptide excision presumably reduces the rigidity of frutalin carbohydrate-binding site, increasing the number of interactions with ligands and resulting in multiple-binding sites and anomeric recognition of $\alpha$-D-galactose sugar moieties [15]. Nevertheless, the loss in sugar binding affinity did not compromise the ability of jacalin or frutalin to recognize cancer cells $[4,9,19]$. 


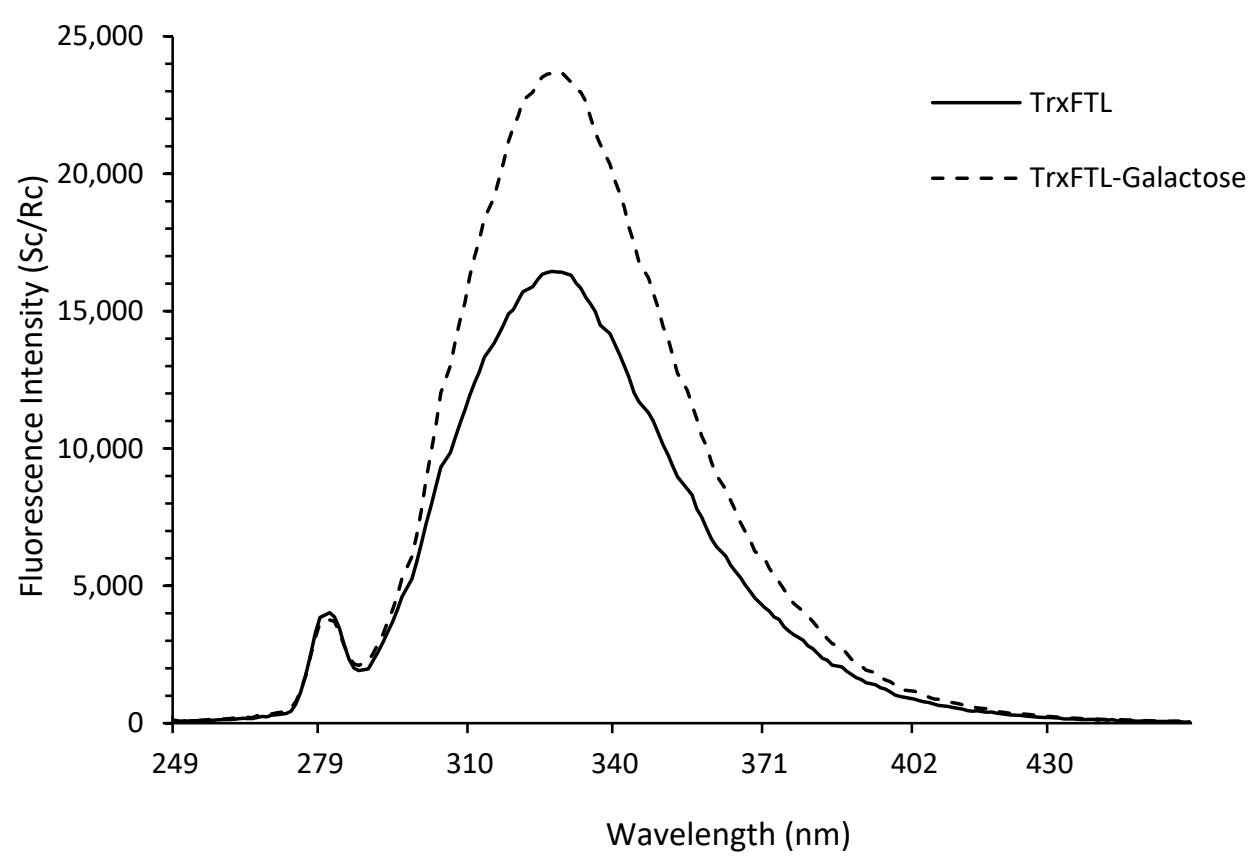

Figure 5. Fluorescence emission spectra of TrxFTL in the absence (solid line) and presence (dashed line) of methyl- $\alpha$-galactose in PBS.

\subsection{Antitumor Activity}

The growth inhibitory effect of TrxFTL and cFTL was initially compared in the human cancer cell line HCT116 $\mathrm{p}^{+/+}$. An identical dose-response curve was obtained for the two recombinant forms, showing once more that the TrxA tag does not interfere with frutalin activity, in agreement with the DLS and hemagglutination assays. Then, TrxFTL was further evaluated in a panel of distinct human cancer cell lines of colon (HCT116 p53 $3^{+/+}$ and HCT116 $\mathrm{p}^{-/-}$), melanoma (A375), triple-negative breast cancer (MDA-MB-231), and ovarian (IGROV-1), using the SRB assay. A dose-response curve was obtained for TrxFTL in the distinct cancer cells and the $\mathrm{GI}_{50}$ was determined after $48 \mathrm{~h}$ treatment (Table 2; Figure 6). TrxFTL inhibited the growth of HCT116, A375, IGROV-1, and MDA-MB-231 cells. Interestingly, this anti-proliferative effect of TrxFTL revealed to involve the p53 pathway since it was significantly reduced in p53-null HCT116 cells (HCT116 p53-/-), when compared to the isogenic HCT116 $\mathrm{p}^{+/+}$cells (Table 2). It should also be noted that the effectiveness of TrxFTL on MDA-MB-231 cells, expressing mutant p53, might indicate its ability to target both wild type and mutant p53 forms. In the non-tumor colon cancer cell line CCD-18Co, the $\mathrm{GI}_{50}$ value was approximately 2 -fold higher than that obtained in the HCT116 $53^{+/+}(16.5 \pm 2.2 \mu \mathrm{M}, n=4$ independent experiments), which revealed some selectivity of TrxFTL for the tumor cells of the colonic tissue. 


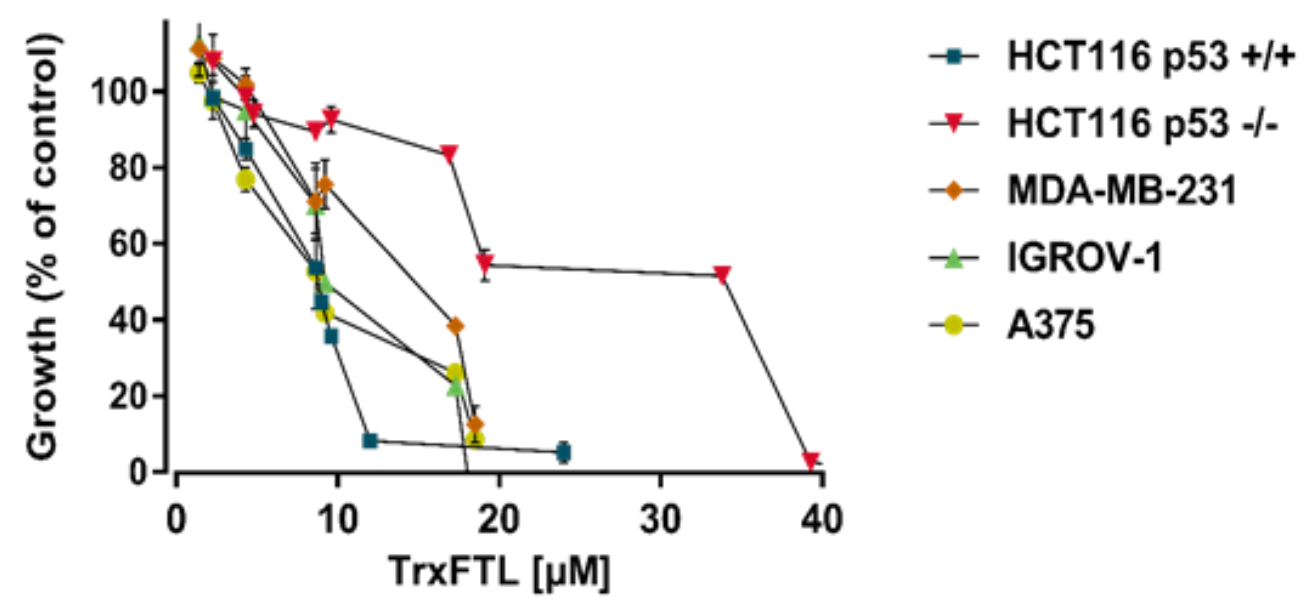

Figure 6. Dose-response curves of the growth inhibitory effect of TrxFTL on human cancer cell lines, determined by the SRB assay, after $48 \mathrm{~h}$ treatment. Data are shown as mean \pm SEM $(n=4-6$ independent experiments).

Table 2. Effect of frutalin produced in E. coli in fusion with TrxA (TrxFTL) on the growth of different human cancer cell lines and effect of frutalin produced in P. pastoris on the growth of HCT116 $553^{+/+}$ cell line (control).

\begin{tabular}{ccc}
\hline Frutalin Version & Cancer Cell Lines & GI $_{\mathbf{5 0}}(\boldsymbol{\mu M})$ \\
\hline Frutalin produced in P. pastoris & HCT116 p53 & $8.5 \pm 0.6$ \\
\hline & HCT116 p53 & $8.7 \pm 2.6$ \\
Frutalin produced in E. coli in fusion & HCT116 p53 & $25.0 \pm 3.0^{* *}$ \\
with TrxA (TrxFTL) & A375 & $8.5 \pm 0.8$ \\
& IGROV-1 & $10.3 \pm 0.7$ \\
& MDA-MB-231 & $11.8 \pm 1.1$ \\
\hline
\end{tabular}

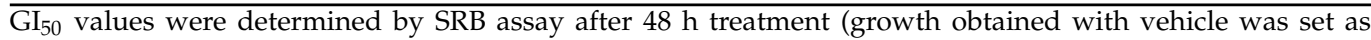
$100 \%$ ). Data are shown as mean \pm SEM of four to six independent experiments; values of HCT116 p53-/- cells

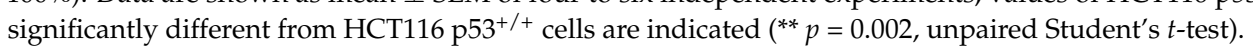

\section{Discussion}

In this work, a frutalin isoform with anticancer activity was produced in E. coli in fusion with TrxA, for enhancing its solubility and yield, and His6, for facilitating its purification. TrxFTL appeared in SDS-PAGE gel as a single band of $\sim 32 \mathrm{kDa}$, whereas cleaved FTL migrated in gel as a single band of $\sim 17 \mathrm{kDa}$ (Figure 1), which is in complete agreement with MW of previous recombinant frutalin either expressed in bacteria or yeast hosts [6,8]. As expected, a good yield of purified protein was obtained, $66 \mathrm{mg}$ of protein per liter of culture, which was exceptionally higher (868-fold increase) than the first yield obtained in E. coli, $76 \mu \mathrm{g}$ of pure frutalin per liter of E. coli culture [6]. When a microbial host of higher production capacity was employed, P. pastoris, the same frutalin isoform could be obtained at the maximum of $20 \mathrm{mg}$ per liter of culture [8]. This means that a 3.3-fold improvement in frutalin yield was achieved in this work. Furthermore, the production and purification protocols were much simplified: shake-flask production was reduced from 5-days to 1-day, and purification, although still consisting in two steps (affinity chromatography plus buffer exchange), was faster and less prone to losses than previous method (size-exclusion chromatography plus concentration by ultrafiltration) [8]. However, one limitation of using the E. coli expression system could have been the lack of proper glycosylation, since frutalin is a partly glycosylated lectin in nature. For this reason, the biological activity of TrxFTL was investigated in detail. Unlike other frutalin isoform [6], and native frutalin [18], TrxFTL and cFTL did not present hemagglutinating activity (Figure 4). This result cannot be attributed to conformation issues since the native tetrameric frutalin structure was suggested to be present in TrxFTL and cFTL by DLS 
analysis (Figure 3). This result explains that the lack of hemagglutination activity in the same tetrameric isoform obtained in yeast is not due to Pichia glycosylation pattern. Then, it can be concluded that different frutalin isoforms have different biological activities, as reported for other lectins that are also comprised by a mixture of isoforms [5]. Other observations indicated that the activity of frutalin recombinantly obtained in bacteria is identical to the one obtained in Pichia. TrxFTL strongly interacted with methyl- $\alpha$-galactose (Figure 5), but not with galactose, like frutalin recombinantly produced in yeast [8]. In addition, it showed antiproliferative activity against cancer cells, either in fusion or cleaved from partners. Results of TrxFTL in $\mathrm{HCT} 116^{+/+}$cells are quite close to results obtained with same frutalin isoform produced in P. pastoris, which showed a GI $\mathrm{I}_{50}$ of $8.5 \pm 0.6 \mu \mathrm{M}$ (Table 2). Frutalin obtained in yeast also presented a dose-dependent cytotoxicity on human cervical cancer cells, HeLa cells $\left(\mathrm{GI}_{50} \sim 6 \mu \mathrm{M}\right)$, whose results were in accordance with native frutalin effects [4]. Since the two frutalin versions of same isoform, partly glycosylated [8] and non-glycosylated (this work), have identical magnitude of cytotoxicity on human cancer cells, it can be concluded that glycosylation is not involved on this activity. This work is in line with other studies reporting that the biological activities of lectins are independent of glycosylation $[5,7,20]$. This work also shows, for the first time, the cytotoxic effect of frutalin on melanoma, ovarian and triple-negative breast cancer cell lines, which further reinforces the great potential of recombinant frutalin as an anti-cancer drug (Table 2; Figure 6).

The cytotoxicity of plant lectins has been extensively studied on a diversity of cancer cell lines (for a revision, see e.g., Table 3 in [21]). For example, very recently, the antiproliferative activity of the galactose-binding plant lectin BfL-II, produced and purified from E. coli, was evaluated in human breast (MCF-7) and colorectal (HT-29) cancer cells, showing to be stronger on colorectal cancer cells, while at much higher concentration than frutalin [20]. Plant lectins exert their antiproliferative activity by inducing programmed cell death pathways (apoptosis and/or autophagy). Frutalin has been shown to induce cell death on HeLa cells by apoptosis [4]. The possible molecular mechanism by which plant lectins induce tumor cell death by apoptosis involves, at first place, the lectin interaction with sugar binding receptors present on the plasma membrane, followed by internalization through endocytosis [22]. This event has been previously observed in the interaction of frutalin produced in P. pastoris, and native frutalin, with HeLa cells [4]. Rapidly (within 1-h incubation), both frutalin versions were completely internalized and detected around and inside HeLa nucleus [4]. Sugar binding receptors of jacalin-related lectins, to which family frutalin belongs, are mostly Tn, sTn, and T antigens [21]. These abnormal O-glycans are expressed on several types of cancer, including colon or breast cancers, and are associated with adverse outcomes and poor prognosis [23]. The structure of many lectins, including jacalin, in complex with $\mathrm{T}$ antigens have been previously revealed [24]. Interestingly, strong interaction of native frutalin with $\mathrm{T}$ antigen $(\mathrm{Galb}(1-3) \mathrm{GalNac})$ was observed in our previous work, but no interaction with this sugar could be detected for frutalin produced in yeast [8]. This result suggests the presence of other frutalin receptors, such as methylated glycans, rather than $\mathrm{T}$ antigens. Once inside the cells, the lectins can trigger an apoptotic cell death mostly through a mitochondria-mediated pathway, involving relevant players such as p53 [22]. Accordingly, activation of the p53 pathway has already been reported for certain plant lectins. For example, recently, the bean lectin TBLF has shown to induce apoptosis in colon cancer cells by p-p53(ser46) involvement [25]. Nevertheless, no involvement of jacalin-related lectins with p53 pathway has been described so far. Our work adds a novel and important clue on the mechanism underlying frutalin-induced cancer cell death. In fact, the results herein obtained indicate a potential involvement of the p53 pathway in the antiproliferative activity of TrxFTL. Therefore, in a future work, it would be very interesting to deeply elucidate this potential p53-dependent antitumor activity of frutalin.

In conclusion, fusion tag technology was effective in improving frutalin yield in E. coli, not interfering with frutalin bioactivity. Moreover, frutalin was obtained in this host as an active anticancer molecule of broad spectrum, which deserves to be further explored based on its great potential in targeted anticancer therapy. 


\section{Materials and Methods}

\subsection{Construction of Expression Vector}

Frutalin mature sequence [8], with codons optimized for recombinant expression in E. coli, flanked by NcoI and XhoI recognition sites at the $5^{\prime}$ - and $3^{\prime}$-end, respectively, was synthesized by NZYTech. The frutalin synthetic gene was excised from the carrying plasmid by digestion with $\mathrm{NcoI}$ and XhoI enzymes and ligated to the pETM20 vector (EMBL) in fusion with the N-terminal thioredoxin A (TrxA) and His6 tags (linked to the cloning site by a TEV protease recognition sequence) [14]. The construct was transformed and propagated in chemically competent NZY5a E. coli cells (NZYTech). For protein expression, the construct was transformed into the E. coli strain NZYBL21 (DE3) (NZYTech).

\subsection{Recombinant Protein Production and Purification}

E. coli BL21(DE3) cells harboring the recombinant plasmid were grown overnight at $37^{\circ} \mathrm{C}$ in $10 \mathrm{~mL} \mathrm{LB}$ medium containing $100 \mu \mathrm{g} / \mathrm{mL}$ of ampicillin. In the day after, $4 \times 250 \mathrm{~mL}$ of same medium were inoculated with previous culture (1:1000) and grown to an OD600 $\mathrm{nm}$ of 0.5 and recombinant protein expression induced with $0.2 \mathrm{mM}$ IPTG for $16 \mathrm{~h}$ at $18{ }^{\circ} \mathrm{C}$. Cells were recovered by centrifugation (at $4{ }^{\circ} \mathrm{C}$ for $15 \mathrm{~min}$ at $10,000 \mathrm{rpm}$ ) and lysed with NZY Bacterial Cell Lysis Buffer (NZYTech) supplemented with $1 \mathrm{mM}$ PMSF, according to the manufacturer's instructions. Soluble cell-free extracts were collected by centrifugation, filtered $(0.45 \mu \mathrm{M}$ pore size), and loaded on a $5 \mathrm{~mL}$ Nickel HisTrap column (GE Healthcare) for recombinant protein purification by immobilized metal ion affinity chromatography (IMAC). Purification was conducted according to the manufacturer's instructions, using $50 \mathrm{mM}$ Tris $\mathrm{pH} 8.0,150 \mathrm{mM} \mathrm{NaCl}$ with 20 or $40 \mathrm{mM}$ imidazole as running and washing buffer, respectively, and with $300 \mathrm{mM}$ imidazole for the elution buffer [14].

For TrxA-His6 partner removal, the purified fusion protein was digested with TEVHis6 protease overnight at $4{ }^{\circ} \mathrm{C}$ at the ratio of $1: 20(w / w)$ in running buffer. Elution buffer was previously exchanged with running buffer using PD10 columns (GE Healthcare). The cleaved frutalin was then purified from the fusion tags and protease through reverse purification by incubation with $0.5 \mathrm{~mL}$ of HisPur ${ }^{\mathrm{TM}}$ Ni-NTA Resin (Thermo Fisher Scientific), following manufacturer's instructions as given for the batch purification method, using the above-mentioned buffers, but in which the target protein (cFTL) was collected from the resin washing steps.

Purified proteins were analyzed by SDS-PAGE using 15\% (w/v) acrylamide gels, followed by BlueSafe staining (NZYTech). Imidazole removal from proteins, and any other buffer exchange, was performed using PD10 columns (GE Healthcare). The concentration of the recombinant proteins was estimated from the absorbance at $280 \mathrm{~nm}$ using the respective molar extinction coefficients. Recombinant proteins were maintained at $4{ }^{\circ} \mathrm{C}$ until their use in subsequent in vitro studies.

\subsection{Dynamic Light Scattering (DLS)}

The size distribution of protein samples was determined with a Malvern Zetasizer, MODEL NANO ZS (Malvern Instruments Limited, Worcestershire, UK). Protein in phosphate buffer $(1 \mathrm{~mL})$ at a concentration between $0.8-1.0 \mathrm{mg} / \mathrm{mL}$ was analyzed at room temperature using a polystyrene cell. Ten measurements per sample were performed. Protein samples were filtrated through $0.45 \mu \mathrm{m}$ pore. Zetasizer software tool "MW \& Shape Estimates" (Worcestershire, UK) was used to determine expected hydrodynamic radius using theoretical MW of proteins. The online ExPASy ProtParam tool was used to calculate MW of proteins using primary amino acid sequences.

\subsection{Hemagglutination Assays}

Hemagglutinating studies were conducted as previously reported [8]. Briefly, lectins were mixed 1:2 with a rabbit erythrocytes solution $(2 \%(v / v)$ in $0.15 \mathrm{M} \mathrm{NaCl})$ in the range $0.002-0.2 \mathrm{mg} / \mathrm{mL}$ in Eppendorfs, and incubated at $37^{\circ} \mathrm{C}$ for $30 \mathrm{~min}$, plus another $30 \mathrm{~min}$ at 
room temperature. Thereafter, samples were visually inspected for the presence or absence of agglutination. Native frutalin, obtained as previously described [8], was included as positive control. Three independent assays were performed.

\subsection{Recombinant Frutalin Three-Dimensional (3D) Model Building}

The fully automated protein homology-modelling server SWISS-MODEL [26] was used to predict and evaluate the 3D model structure of recombinant frutalin. The X-ray crystal structure of the frutalin from Artocarpus incisa (PDB ID: 4WOG) served as template. Molecular illustrations were prepared using VMD [27].

\subsection{Fluorescence Studies}

Fluorescence studies were performed as previously described [8] using Spectrofluorometer Horiba Aqualog 800 (Boeblingen, Germany). Gains in the intrinsic fluorescence emission of recombinant frutalin in the presence of the non-fluorescent sugar methyl- $\alpha$ galactose $(100 \mathrm{mM})$ were recorded at $328 \mathrm{~nm}$. Data was analyzed using OriginPro 2015 software ((Boeblingen, Germany).

\subsection{Human Cancer Cell Lines and Growth Conditions}

Human colon adenocarcinoma HCT116 cell lines, expressing p53 (HCT116 p53 ${ }^{+/+}$)

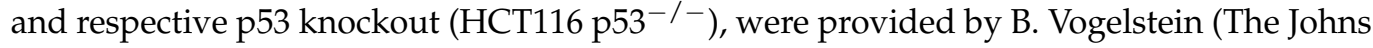
Hopkins Kimmel Cancer Center, Baltimore, MD, USA); melanoma A375 cell line was purchased from CLS Cell Lines Service GmbH (Eppelheim, Germany); human ovarian carcinoma IGROV-1 was provided by Professor Leonor David from Instituto de Investigação e Inovação em Saúde, i3S (Porto, Portugal), human breast adenocarcinoma MDA-MB-231 and normal colon CCD-18Co cell lines were purchased from ATCC (Manassas, VA, USA). Human cell lines used were routinely cultured in RPMI-1640 medium with UltraGlutamine (Lonza, VWR), excepting CCD-18Co cells that were cultured in EMEM (Lonza, Ingrenor, Porto, Portugal), supplemented with 10\% fetal bovine serum (FBS; Gibco, Alfagene, Lisboa, Portugal), and maintained at $37{ }^{\circ} \mathrm{C}$ with $5 \% \mathrm{CO}_{2}$. Cells were routinely tested for mycoplasma infection using the MycoAlert ${ }^{\mathrm{TM}}$ PLUS mycoplasma detection kit (Lonza).

\subsection{Sulforhodamine B (SRB) Assay}

Human cell lines were seeded in 96-well plates at a density of $5.0 \times 10^{3}$ cells / well (for $\mathrm{p} 53^{+/+}$and $\mathrm{p} 53^{-/-}$HCT116, IGROV-1, MDA-MB-231, and CCD-18Co cells) and $4.5 \times 10^{3}$ cells / well (for A375 cells) for $24 \mathrm{~h}$. Cells were treated with serial dilutions of TrxFTL for additional $48 \mathrm{~h}$. Recombinant frutalin from $P$. pastoris, obtained as previously described [8], was included as positive control. Effects on cell proliferation were measured by SRB assay, as previously described [28], and the concentration that induced half of growth inhibition $\left(\mathrm{GI}_{50}\right)$ was determined for each cell line using the GraphPad Prism software version 7.0 (La Jolla, CA, USA).

Since the effects of TrxFTL and cFTL on cancer cells were identical, this study was conducted with TrxFTL, to avoid extra purification steps of recombinant frutalin.

\subsection{Statistical Analysis}

Statistical significance was calculated for each data set based on at least three independent experiments. Data were analyzed using GraphPad Prism software v7.0 (San Diego, CA, USA) and are presented as means \pm SEM. Unpaired Student's $t$-test (two-tailed) was applied to each dataset in order to compare average values; $p<0.05$ was considered statistically significant.

Author Contributions: Conceptualization, C.O., L.S., and L.D.; methodology, C.O., A.I.F., N.C., and L.D.; investigation, C.O., A.I.F., and N.C.; data curation, C.O.; writing-original draft preparation, C.O.; writing-review and editing, C.O., A.I.F., L.S., and L.D.; supervision, L.S. and L.D.; funding acquisition, L.S. and L.D. All authors have read and agreed to the published version of the manuscript. 
Funding: This research was supported by the Portuguese Foundation for Science and Technology (FCT) under the scope of the strategic funding of UIDB/04469/2020 and UIDB/50006/2020 (LAQV/REQUIMTE).

Conflicts of Interest: The authors declare no conflict of interest.

Sample Availability: Samples of the compounds are available from the authors at reasonable request.

\section{References}

1. Abdon, A.P.V.; De Souza, G.C.; De Souza, L.N.C.; Vasconcelos, R.P.; Castro, C.A.; Guedes, M.M.; Júnior, R.C.P.L.; Moreira, R.D.A.; Monteiro-Moreira, A.C.; Campos, A.R. Gastroprotective potential of frutalin, a d-galactose binding lectin, against ethanol-induced gastric lesions. Fitoterapia 2012, 83, 604-608. [CrossRef] [PubMed]

2. de Sousa, F.D.; Vasconselos, P.D.; da Silva, A.F.B.; Mota, E.F.; Tomé, A.D.R.; Mendes, F.R.D.S.; Gomes, A.M.M.; Abraham, D.J.; Shiwen, X.; Owen, J.S.; et al. Hydrogel and membrane scaffold formulations of Frutalin (breadfruit lectin) within a polysaccharide galactomannan matrix have potential for wound healing. Int. J. Biol. Macromol. 2019, 121, 429-442. [CrossRef]

3. Araújo, J.R.C.; Júnior, J.D.M.A.D.M.; Damasceno, M.D.B.M.V.; Santos, S.A.A.R.; Vieira-Neto, A.E.; Lobo, M.D.P.; Campos, A.R.; Moreira, R.D.A.; Monteiro-Moreira, A.C.D.O. Neuropharmacological characterization of frutalin in mice: Evidence of an antidepressant-like effect mediated by the NMDA receptor/NO/cGMP pathway. Int. J. Biol. Macromol. 2018, 112, 548-554. [CrossRef] [PubMed]

4. Oliveira, C.; Nicolau, A.; Teixeira, J.A.; Domingues, L. Cytotoxic Effects of Native and Recombinant Frutalin, a Plant GalactoseBinding Lectin, on HeLa Cervical Cancer Cells. J. Biomed. Biotechnol. 2011, 2011, 1-9. [CrossRef] [PubMed]

5. Oliveira, C.; Teixeira, J.; Domingues, L. Recombinant lectins: An array of tailor-made glycan-interaction biosynthetic tools. Crit. Rev. Biotechnol. 2012, 33, 66-80. [CrossRef] [PubMed]

6. Oliveira, C.; Costa, S.; Teixeira, J.; Domingues, L. cDNA Cloning and Functional Expression of the $\alpha$-d-Galactose-Binding Lectin Frutalin in Escherichia coli. Mol. Biotechnol. 2009, 43, 212-220. [CrossRef]

7. Biswas, H.; Chattopadhyaya, R. Stability ofCurcuma longarhizome lectin: Role of N-linked glycosylation. Glycobiology 2015, 26, 410-426. [CrossRef]

8. Oliveira, C.; Felix, W.; Moreira, R.D.A.; Teixeira, J.; Domingues, L. Expression of frutalin, an $\alpha$-d-galactose-binding jacalin-related lectin, in the yeast Pichia pastoris. Protein Expr. Purif. 2008, 60, 188-193. [CrossRef]

9. Oliveira, C.; Teixeira, J.A.; Schmitt, F.; Domingues, L. A comparative study of recombinant and native frutalin binding to human prostate tissues. BMC Biotechnol. 2009, 9, 78. [CrossRef]

10. Yadav, D.K.; Yadav, N.; Yadav, S.; Haque, S.; Tuteja, N. An insight into fusion technology aiding efficient recombinant protein production for functional proteomics. Arch. Biochem. Biophys. 2016, 612, 57-77. [CrossRef] [PubMed]

11. Oliveira, C.; Domingues, L. Guidelines to reach high-quality purified recombinant proteins. Appl. Microbiol. Biotechnol. 2017, 102, 81-92. [CrossRef]

12. Ki, M.-R.; Pack, S.P. Fusion tags to enhance heterologous protein expression. Appl. Microbiol. Biotechnol. 2020, 104, 2411-2425. [CrossRef]

13. Ramos, R.; Domingues, L.; Gama, M. Escherichia coli expression and purification of LL37 fused to a family III carbohydratebinding module from Clostridium thermocellum. Protein Expr. Purif. 2010, 71, 1-7. [CrossRef]

14. Costa, S.J.; Almeida, A.; Castro, A.; Domingues, L.; Besir, H. The novel Fh8 and H fusion partners for soluble protein expression in Escherichia coli: A comparison with the traditional gene fusion technology. Appl. Microbiol. Biotechnol. 2012, 97, 6779-6791. [CrossRef]

15. Vieira-Neto, A.E.; De Sousa, F.D.; Pereira, H.D.; Moreno, F.B.M.B.; Lourenzoni, M.R.; Grangeiro, T.B.; Monteiro-Moreira, A.C.D.O.; Moreira, R.D.A. New structural insights into anomeric carbohydrate recognition by frutalin: An $\alpha$-d-galactose-binding lectin from breadfruit seeds. Biochem. J. 2019, 476, 101-113. [CrossRef]

16. Moreira, R.D.A.; Castelo-Branco, C.; Monteiro, A.C.; Tavares, R.O.; Beltramini, L. Isolation and partial characterization of a lectin from Artocarpus incisa L. seeds. Phytochemistry 1998, 47, 1183-1188. [CrossRef]

17. Klafke, G.B.; Moreira, G.M.S.G.; Pereira, J.L.; Oliveira, P.D.; Conceição, F.R.; Lund, R.G.; Grassmann, A.A.; Dellagostin, O.A.; Pinto, L.D.S. Lectin I from Bauhinia variegata (BVL-I) expressed by Pichia pastoris inhibits initial adhesion of oral bacteria in vitro. Int. J. Biol. Macromol. 2016, 93, 913-918. [CrossRef] [PubMed]

18. Sahasrabuddhe, A.A.; Gaikwad, S.M.; Krishnasastry, M.; Khan, M.I. Studies on recombinant single chain Jacalin lectin reveal reduced affinity for saccharides despite normal folding like native Jacalin. Protein Sci. 2009, 13, 3264-3273. [CrossRef] [PubMed]

19. Sahasrabuddhe, A.; Ahmed, N.; Krishnasastry, M. Stress-induced phosphorylation of caveolin-1 and p38, and down-regulation of EGFr and ERK by the dietary lectin jacalin in two human carcinoma cell lines. Cell Stress Chaperon 2006, 11, 135-147. [CrossRef] [PubMed]

20. Pinto, L.D.S.; Cardoso, G.; Kremer, F.S.; Woloski, R.D.D.S.; Dellagostin, O.A.; Campos, V.F. Heterologous expression and characterization of a new galactose-binding lectin from Bauhinia forficata with antiproliferative activity. Int. J. Biol. Macromol. 2019, 128, 877-884. [CrossRef]

21. Poiroux, G.; Barre, A.; Van Damme, E.J.M.; Benoist, H.; Rougé, P. Plant Lectins Targeting O-Glycans at the Cell Surface as Tools for Cancer Diagnosis, Prognosis and Therapy. Int. J. Mol. Sci. 2017, 18, 1232. [CrossRef] [PubMed] 
22. Bhutia, S.K.; Panda, P.K.; Sinha, N.; Praharaj, P.P.; Bhol, C.S.; Panigrahi, D.P.; Mahapatra, K.K.; Saha, S.; Patra, S.; Mishra, S.R.; et al. Plant lectins in cancer therapeutics: Targeting apoptosis and autophagy-dependent cell death. Pharmacol. Res. 2019, 144, 8-18. [CrossRef] [PubMed]

23. Fu, C.; Zhao, H.; Wang, Y.; Cai, H.; Xiao, Y.; Zeng, Y.; Chen, H. Tumor-associated antigens: Tn antigen, sTn antigen, and T antigen. HLA 2016, 88, 275-286. [CrossRef]

24. Jeyaprakash, A.; Rani, P.G.; Reddy, G.B.; Banumathi, S.; Betzel, C.; Sekar, K.; Surolia, A.; Vijayan, M. Crystal Structure of the Jacalin-T-antigen Complex and a Comparative Study of Lectin-T-antigen Complexes. J. Mol. Biol. 2002, 321, 637-645. [CrossRef]

25. Moreno-Celis, U.; López-Martínez, F.J.; Cervantes-Jiménez, R.; Ferríz-Martínez, R.A.; Blanco-Labra, A.; García-Gasca, T. Tepary Bean (Phaseolus acutifolius) Lectins Induce Apoptosis and Cell Arrest in G0/G1 by P53(Ser46) Phosphorylation in Colon Cancer Cells. Molecules 2020, 25, 1021. [CrossRef] [PubMed]

26. Biasini, M.; Bienert, S.; Waterhouse, A.; Arnold, K.; Studer, G.; Schmidt, T.; Kiefer, F.; Cassarino, T.G.; Bertoni, M.; Bordoli, L.; et al. SWISS-MODEL: Modelling protein tertiary and quaternary structure using evolutionary information. Nucleic Acids Res. 2014, 42, W252-W258. [CrossRef]

27. Humphrey, W.; Dalke, A.; Schulten, K. VMD: Visual molecular dynamics. J. Mol. Graph. 1996, 14, 33-38. [CrossRef]

28. Soares, J.; Raimundo, L.; Pereira, N.A.; dos Santos, D.; Pérez, M.; Queiroz, G.; Leão, M.; Santos, M.; Saraiva, L. A tryptophanolderived oxazolopiperidone lactam is cytotoxic against tumors via inhibition of p53 interaction with murine double minute proteins. Pharmacol. Res. 2015, 95-96, 42-52. [CrossRef] 